Check for updates

Cite this: RSC Adv., 2017, 7, 39786

Received 19th June 2017

Accepted 8th August 2017

DOI: $10.1039 / \mathrm{c} 7 \mathrm{ra06798d}$

rsc.li/rsc-advances

\title{
Synthesis and properties of an intrinsic flame retardant silicone rubber containing phosphaphenanthrene structure
}

\begin{abstract}
Wei Chen, ${ }^{a}$ Yuansen Liu, ${ }^{b}$ Changan $X u^{* b}$ Yuan Liu (D) *a and Qi Wang ${ }^{a}$
A novel intrinsic flame retardant silicone rubber (SR) containing phosphaphenanthrene structure was synthesized in the present research. A series of characterizations including vertical burning testing, limiting oxygen index (LOI), microscale combustion calorimetry (MCC), thermogravimetric (TG) analysis and scanning electronic microscopy (SEM) showed that this SR possessed much quicker selfextinguishment, lower heat release rate, higher LOI and thermal stability as well as better charring capacity compared with unmodified SR. The char residues of the materials had been investigated in detail by Fourier transform infrared spectra (FT-IR) and X-ray photoelectron spectroscopy (XPS) to reveal the interactions between phosphaphenanthrene group and siloxane in the condensed phase. In addition, the corresponding physical properties such as transparence, dynamic and static mechanical performances were also evaluated.
\end{abstract}

\section{Introduction}

As one of the most important synthetic rubbers with excellent high and low temperature resistance, weathering ability, chemical resistance and good transparence, silicone rubber (SR) has been widely used in various fields including electrical industries, aerospace, automobile industry, etc. ${ }^{1,2}$ Over the past 60 years, the fast development of silicone materials has attracted the attention of the world. ${ }^{3}$ Despite that it possesses better flame retardancy as compared to other rubbers, SR exhibits self-sustaining combustion once ignited. This flammability restricts the applications of SR in those fields which have strict fire-proofing requirements. Therefore, it is significant to endow SR with satisfactory flame retardance through some modification methods. ${ }^{4}$ There were many related researches reporting on improving the flame retardance of SR by adding flame retardants or inorganic fillers, ${ }^{4-7}$ such as red phosphorus, clay, $\mathrm{Al}(\mathrm{OH})_{3}$, silica particles, wollastonite and so on. Yang ${ }^{8}$ et al. used a solution intercalation method to prepare methyl vinyl silicone rubber/ montmorillonite nanocomposites, and the composites showed obviously higher thermal stability and flameretardant properties than original SR. Chen et al. ${ }^{9}$ used pen-

\footnotetext{
${ }^{a}$ The State Key Laboratory of Polymer Materials Engineering, Polymer Research Institute of Sichuan University, Chengdu 610065, China. E-mail: liuyuan42001@ 163.com; Fax: +86-28-85402465; Tel: +86-28-85405133

${ }^{b}$ Engineering Research Centre of Marine Biological Resource Comprehensive Utilization, Third Institute of Oceanography, State Oceanic Administration, PR China.E-mail:xuchangan@tio.org.cn
}

taerythritol, $\mathrm{POCl}_{3}$ and modified expandable graphite to synthesize a new hybrid intumescent flame retardant added into SR; such a flame retardant system could produce a stable and compact charring layer on the SR surface to realize selfextinguishment. However, the additive-type flame retardants mentioned above also displayed some limitations including a decline of the mechanical properties, decrease of transparency and loss of the elasticity. ${ }^{10}$

In order to overcome the shortcomings of physically adding flame retardants, the preparation of intrinsic flame retardant SR by chemically combining $\mathrm{Br}, \mathrm{Cl}, \mathrm{P}$, etc., is more and more causing the interests of the researchers. However, there is no commercialized intrinsic flame retardant SR reported so far. In the present research, a reactive phosphorus compound, 9,10-dihydro-9-oxa-10-phosphaphenanthrene-10oxide (DOPO) was used to react with the epoxy group of siloxane monomer to obtain a SR containing phosphaphenanthrene structure. The corresponding structure and properties of such an intrinsic flame retardant silicone rubber were analyzed and investigated.

\section{Experimental section}

\subsection{Materials}

9,10-Dihydro-9-oxa-10-phosphaphenanthrene-10-oxide (DOPO) was purchased from Shenzhen Jinlong Chemical Technology Co., Ltd., China. 3-Glycidyloxypropyltrimethoxysiloxane (GS), was purchased from China BlueStar Chengrand Research Institute of Chemical Industry (Chengdu, CHN). Alcohol was supplied by Chengdu kelong chemical reagent factory (Chengdu, CHN). 

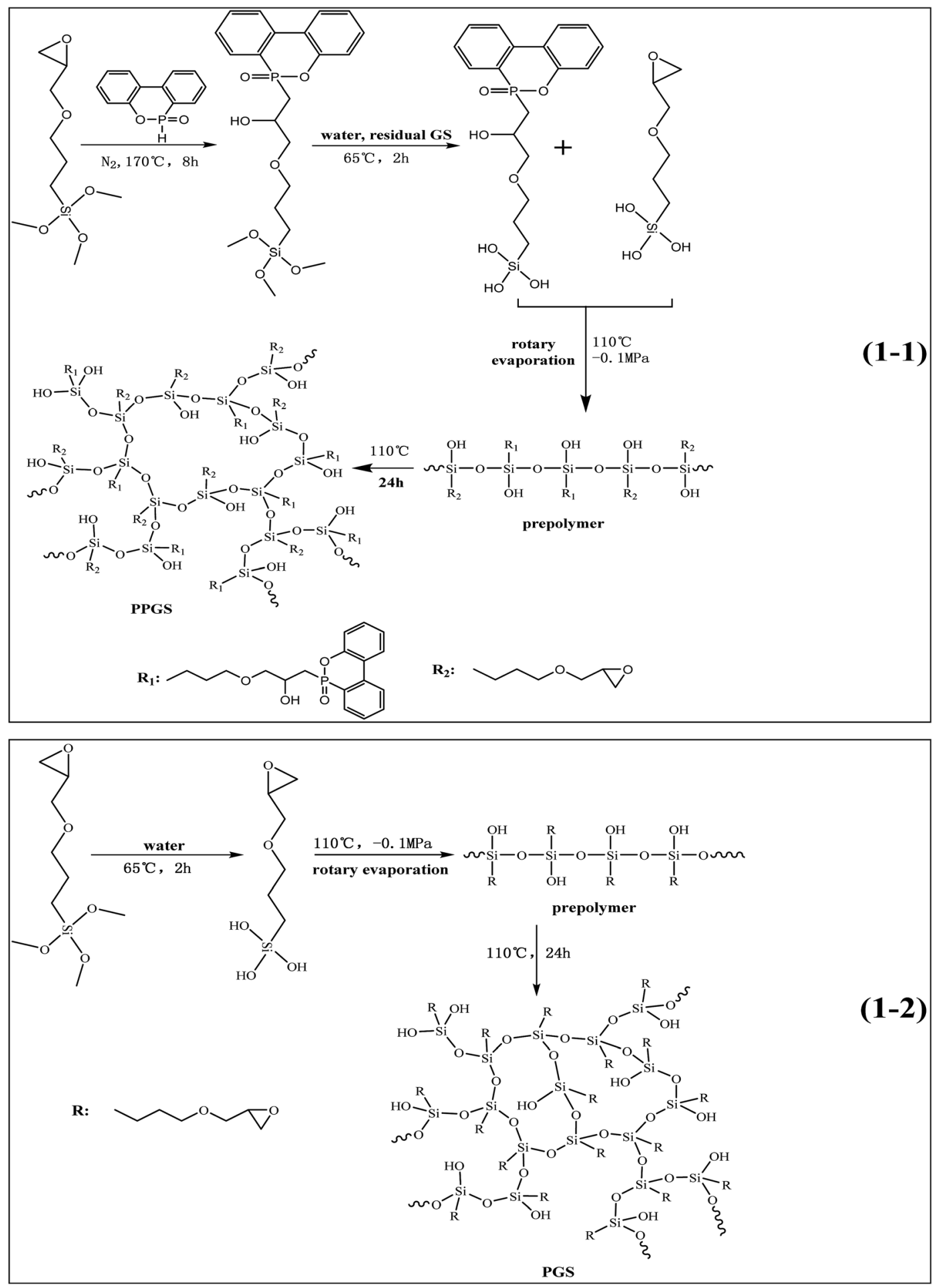

Scheme 1 Synthesis route of PPGS (1-1) and PGS (1-2).

\subsection{Synthesis of PPGS and PGS}

Scheme 1 shows the route of synthesizing PPGS and PGS. $54.00 \mathrm{~g}$ DOPO powder and $118.13 \mathrm{~g}$ GS (the molar ratio is $1: 2$ ) were mixed at $120{ }^{\circ} \mathrm{C}$ until DOPO was dissolved completely in GS, and then the reagents were poured into a three-necked flask equipped with an oil-bath pot, a mechanical stirrer and a reflux condenser. The reaction temperature was maintained at $170{ }^{\circ} \mathrm{C}$ for $8 \mathrm{~h}$ under the atmosphere of nitrogen. After cooling to room temperature, adding $26.9 \mathrm{~g}$ deionized water, the reaction mixture was stirred at $65{ }^{\circ} \mathrm{C}$ for $2 \mathrm{~h}$, then removed the volatiles of low boiling points with rotary evaporation $\left(110^{\circ} \mathrm{C},-0.1 \mathrm{MPa}\right)$ to obtain oily prepolymer. The prepolymer were poured into a mold, and then cured at $110{ }^{\circ} \mathrm{C}$ for $24 \mathrm{~h}$. Finally, adding 
alcohol to wash the products repeatedly for removing the unreacted substance.

The synthesis process of PGS was the same with the second and third step of PPGS.

DOPO/PGS composites was obtained by physically mixing DOPO powder (the same DOPO content with PPGS) and PGS prepolymer together, and then cured in a mold to obtain the final samples.

\subsection{Characterization}

${ }^{13} \mathrm{C}$ and ${ }^{1} \mathrm{H}$ Nuclear Magnetic Resonance (NMR) with prepolymer of PSR was performed using an AVANCE 600 Bruker Spectrometer (Bruker, Switzerland) using dimethyl sulfoxide as a solvent.

FT-IR of PSR were recorded by a Nicolet 20SXB Infrared spectrometer (Thermo Fisher Co, USA), using a diamond single reflection attenuated total reflectance (ATR) accessory equipped by a zinc selenide crystal. The DOPO powder and char were ground and pressed with $\mathrm{KBr}$ respectively.

The vertical burning test was carried out by an HK-HVRA instrument made by Zhuhai Huake Testing Equipment Co. Ltd. (Zhuahai, CHN), with the bar dimensions of $125.0 \times 13.0 \times$ $3.0 \mathrm{~mm}^{3}$ according to ASTM D 3801-10.

LOI was measured using a Dynisco LOI instrument (Dynisco, USA), with the bar dimensions of $150.0 \times 10.0 \times 4.0 \mathrm{~mm}^{3}$ according to ASTM D2863-97.

TG in air atmosphere was tested in TGA4000 (PerkinElmer, USA). The samples of $8 \mathrm{mg}$ were examined from the room temperature to $700{ }^{\circ} \mathrm{C}$ at a heating rate of $10{ }^{\circ} \mathrm{C} \mathrm{min}^{-1}$ under a air atmosphere with a flow rate of $60 \mathrm{ml} \mathrm{min}^{-1}$.

MCC test was carried out using a FAA Micro Calorimeter (Fire Testing Technology Co, UK). The samples were heated to $700{ }^{\circ} \mathrm{C}$ at a heating rate of $1{ }^{\circ} \mathrm{C} \mathrm{s}^{-1}$ in a atmosphere that the proportion of nitrogen to oxygen was $8: 2$.

The morphologies of the charring layers of the samples were observed by a scanning electronic microscope (SEM) (JSM5900LV, JEOL Ltd., Tokyo, Japan) with a conductive gold layer coated and with an accelerating voltage of $10 \mathrm{kV}$. The charring samples were obtained after carbonization at $500{ }^{\circ} \mathrm{C}$ for $30 \mathrm{~min}$ in a muffle furnace.

XPS analysis of burned materials was performed using a Shimadzu/Kratos AXIS Ultra DLD multifunctional X-ray photoelectron spectrometer (Manchester, UK).

Dynamic mechanical analysis was undertaken using a dynamic mechanical thermal analysis (DMTA) apparatus (TA DMA Q800, USA). The specimens $(3 \mathrm{~mm} \times 13 \mathrm{~mm} \times 30 \mathrm{~mm})$ were tested in a single bending modes. The thermal transitions were studied in the $-80{ }^{\circ} \mathrm{C}$ to $90{ }^{\circ} \mathrm{C}$ range at a heating rate of $3{ }^{\circ} \mathrm{C} \min ^{-1}$ and at a fixed frequency of $1 \mathrm{~Hz}$.

The test of the light transmission ratio was performed according to ISO13468 standard by WGT-S Transmittance/Haze Meter (Shanghai, CHN). Each sample was measured five times and an average value was obtained.

The tensile tests of the samples were conducted at room temperature with a crosshead speed of $50 \mathrm{~mm} \mathrm{~min}^{-1}$ (ISO527) using a Reger RG L-10 universal mechanical testing machine (Shenzhen, CHN).

\section{Results and discussion}

\subsection{Structural analysis}

Firstly, FT-IR analysis was employed to analyze the structure of the obtained PSR. Fig. 1 showed the FT-IR spectra of DOPO, PGS and PPGS. The spectrum of PPGS seemed to be a typical combination of DOPO and PGS, it included the absorption peak at $1595 \mathrm{~cm}^{-1}, 1478 \mathrm{~cm}^{-1}, 1432 \mathrm{~cm}^{-1}$ which ascribed to stretching vibration of $\mathrm{C}=\mathrm{C}$ from the phenyl group and $757 \mathrm{~cm}^{-1}$ ascribed to deformation vibration of $\mathrm{C}-\mathrm{H}$ from the phenyl group, the absorption peak at $1201 \mathrm{~cm}^{-1}$ attributed to the deviational vibration of $\mathrm{Si}-\mathrm{C}$, the absorption peak at $1102 \mathrm{~cm}^{-1}$ and $1043 \mathrm{~cm}^{-1}$ attributed to the stretching vibration of the Si-O-Si. Particularly, the disappearance of the characteristic absorption peak assigned to $\mathrm{P}-\mathrm{H}$ bonds at $2436 \mathrm{~cm}^{-1}$ suggested that DOPO had been completely consumed during the reaction.

Besides, ${ }^{13} \mathrm{C}$ NMR was utilized to further characterize the fine chemical structure by providing the information on the carbon skeleton as shown in Fig. 2. Comparing the spectra of PGS and PPGS, it could be seen that a series of new absorption peaks appeared in PPGS spectrum relative to PGS one, included the shifts at 120-150 ppm ascribed to phosphaphenanthrene structure, $49.07 \mathrm{ppm}$ to $\mathrm{P}-\mathrm{C}$ and $53.40 \mathrm{ppm}$ to $\mathrm{C}-\mathrm{OH}$. Meanwhile, the peaks shift of the carbon atoms including 21-24 (the number of carbon atoms) displayed small displacement compared with the corresponding ones (15-18) owing to the impact of the phosphaphenanthrene structure. It implied that $\mathrm{P}-\mathrm{H}$ was completely converted to $\mathrm{O}=\mathrm{P}-\mathrm{C}$ bonds.

To further check the ratio of epoxy group and phosphaphenanthrene structure in PPGS, ${ }^{1} \mathrm{H}$ NMR spectra was showed in Fig. 3. In ${ }^{1} \mathrm{H}$ NMR spectrum of PGS, the protons of $-\mathrm{CH}_{2} \mathrm{Si}$-and $-\mathrm{CH}_{2} \mathrm{CSi}$ - were observed at $0.59 \mathrm{ppm}(2 \mathrm{H})$ and $1.57 \mathrm{ppm}(2 \mathrm{H})$ respectively. For epoxy group, the proton of $\equiv \mathrm{CH}$ corresponded to $3.051 \mathrm{ppm}(1 \mathrm{H})$, and the singlet at $2.71 \mathrm{ppm}$ and $2.50 \mathrm{ppm}$ (overlapped by the signal of DMSO) belonged to the two protons of $-\mathrm{CH}_{2}-$. In addition to this, the molar ratio of the protons of $-\mathrm{CH}_{2} \mathrm{Si}$ - to $-\mathrm{CH}_{2} \mathrm{CSi}$ - correspond with the integration value of

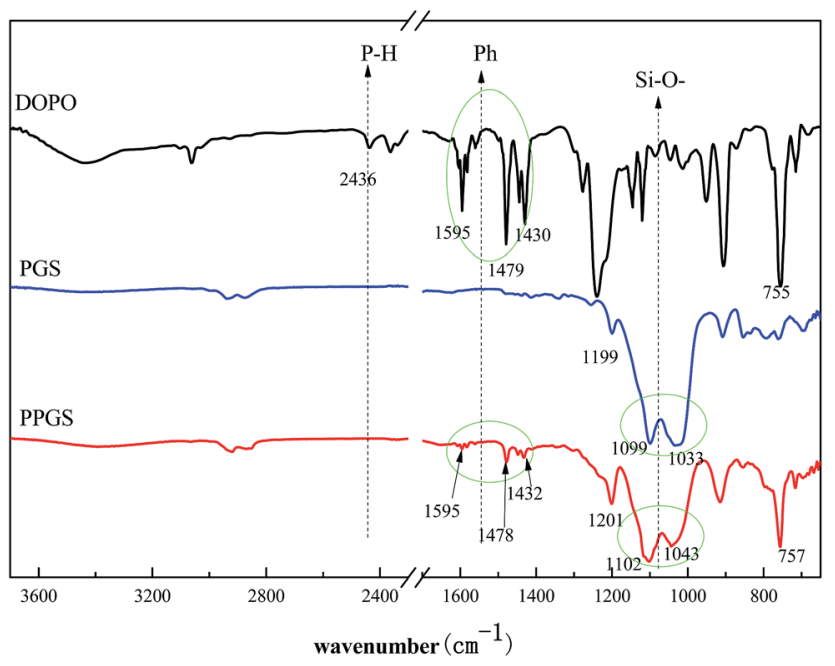

Fig. 1 FT-IR spectra of DOPO, PGS and PPGS. 

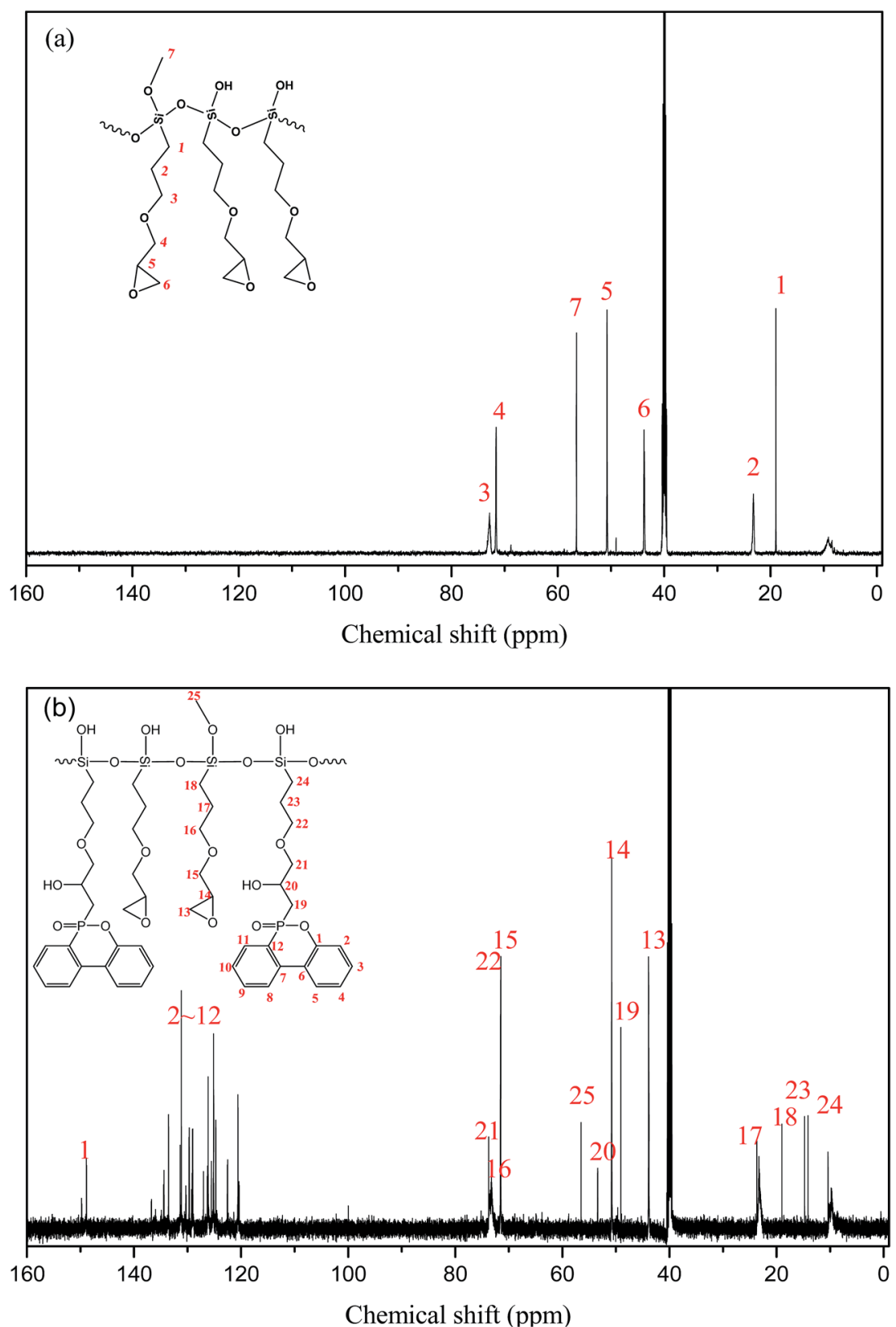

Fig. $2{ }^{13}$ C NMR spectra of the prepolymer of (a) PGS and (b) PPGS.

signals $(6.23: 6.28 \approx 1: 1)$. It was also in accordance with its expected structure.

In ${ }^{1} \mathrm{H}$ NMR spectrum of PPGS, as the protons of $-\mathrm{CH}_{2} \mathrm{O}$ - were overlapped by the signal of $\mathrm{H}_{2} \mathrm{O}$ (from DMSO), the signal of $-\mathrm{CH}_{2} \mathrm{Si}-(0.52 \mathrm{ppm}, 2 \mathrm{H}),-\mathrm{CH}_{2} \mathrm{CSi}-(1.58 \mathrm{ppm}, 2 \mathrm{H})$ were chosen for quantitative determination. The singlet at $3.07 \mathrm{ppm}$ belonged to the proton of $\equiv \mathrm{CH}(1 \mathrm{H})$ of epoxy group, its ratio of the integration value to that of $-\mathrm{CH}_{2} \mathrm{Si}$ - was $0.12: 0.49 \approx 1: 4$, so the molar ratio of epoxy group to $-\mathrm{CH}_{2} \mathrm{Si}-$ was $1: 2$. On the other hand, these signals at 7.2-8.3 ppm attributed to phosphaphenanthrene structure $(8 \mathrm{H})$, the ratio of the integration value to that of $-\mathrm{CH}_{2} \mathrm{Si}-$ was $1.00: 0.49 \approx 2: 1$, so the molar ratio of phosphaphenanthrene structure to $-\mathrm{CH}_{2} \mathrm{Si}-$ was $1: 2$.
Finally, we can obtain the conclusion that the molar ratio of phosphaphenanthrene structure to epoxy group was about $1: 1$.

\subsection{Flame retardancy}

Table 1 exhibited the results of LOI and vertical burning test results of the synthesized SR. The introduction of phosphaphenanthrene structure greatly increased LOI value of PGS. From the combustion process of the above materials (Fig. 4), it could be seen that PGS bar did not extinguish once ignited during vertical flame test. In comparison, PPGS bar quickly selfextinguished after two ignitions. Obviously, the latter showed much better flame retardance and self-extinguishment. 

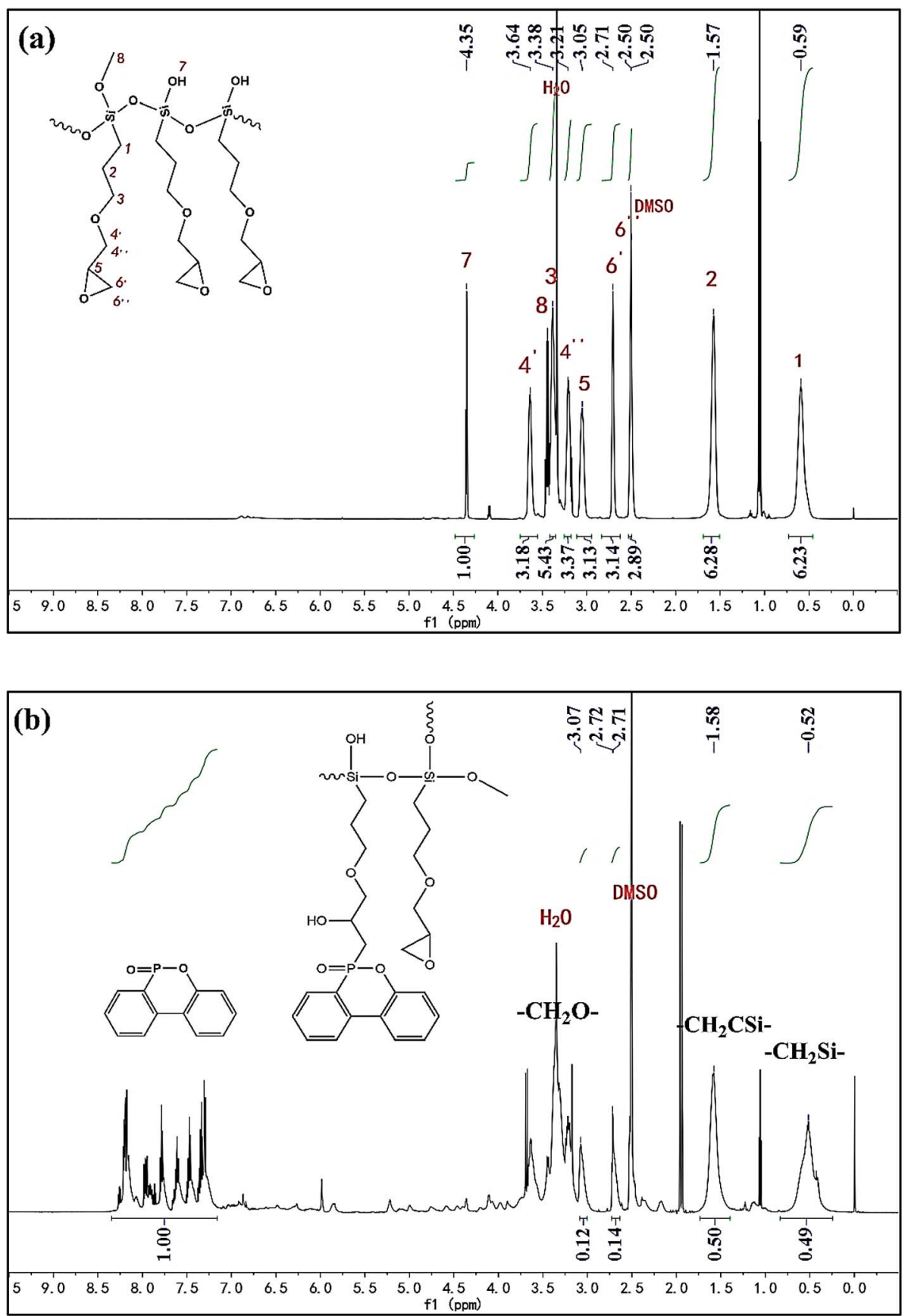

Fig. $3{ }^{1} \mathrm{H}$ NMR spectra of the prepolymer of (a) PGS and (b) PPGS.

Table 1 Vertical burning and LOI tests of PGS and PPGS

\begin{tabular}{lllll}
\hline Samples & LOI $(\%)$ & $\begin{array}{l}\text { Self-extinction time after the first } 10 \mathrm{~s} \\
\text { ignition }\left(t_{1}\right), \mathrm{s}\end{array}$ & $\begin{array}{l}\text { Self-extinction time after the second } 10 \mathrm{~s} \\
\text { ignition }\left(t_{2}\right), \mathrm{s}\end{array}$ & $\begin{array}{l}\text { Flaming } \\
\text { drips }\end{array}$ \\
\hline PGS & 27.6 & No self extinction & - & Nating \\
PPGS & 42.3 & 0 & 0 & NR \\
& & & & None
\end{tabular}

MCC is a convenient way to study the calorimetric behavior and combustion parameters of materials. Fig. 5 showed the HRR curves and the corresponding MCC data of the PGS and
PPGS. It can be seen that with the introduced of phosphaphenanthrene structure, the peak heat release rate (PHRR) was decreased from $223.8 \mathrm{~W} \mathrm{~g}^{-1}$ to $98.25 \mathrm{~W} \mathrm{~g}^{-1}$, total heat release 

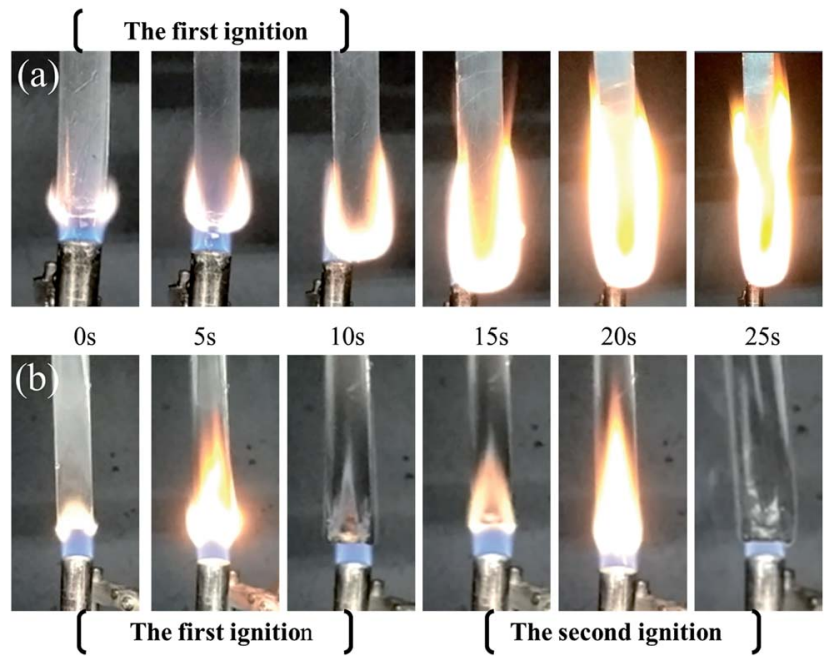

$15 \mathrm{~s}$ $20 \mathrm{~s}$ $25 \mathrm{~s}$

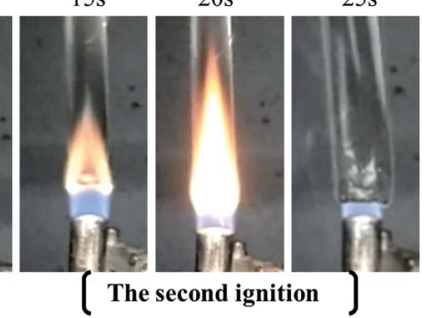

Fig. 4 The combustion process of (a) PGS and (b) PPGS.

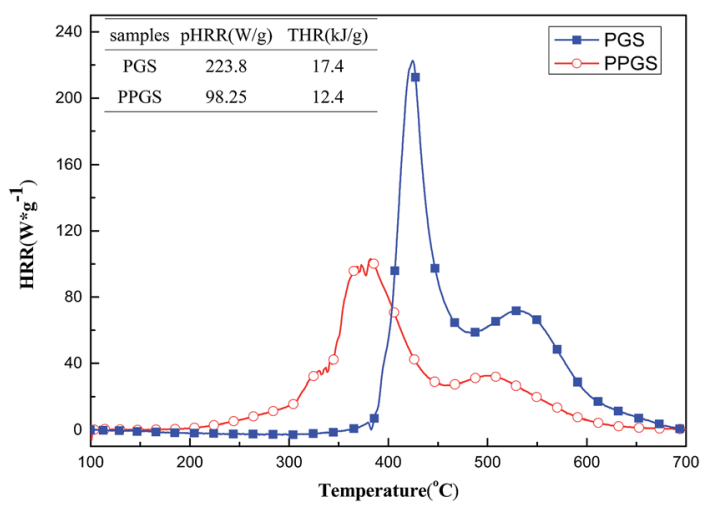

Fig. 5 HRR curves of PGS and PPGS.

(THR) was decreased from $17.4 \mathrm{~kJ} \mathrm{~g}^{-1}$ to $12.4 \mathrm{~kJ} \mathrm{~g}^{-1}$. The calorimetric analysis results in accordance with the previous real flame tests.

Fig. 6 showed thermogravimetric analysis of the above materials in air atmosphere. Due to the typical rigid structure of the introduced DOPO, the thermal stability of PPGS was greatly improved. From the DTG curves, the maximum decomposition temperature ( $T_{\max }$ ) of PGS was only $326^{\circ} \mathrm{C}$, but $T_{\max }$ of PPGS was increased to $388^{\circ} \mathrm{C}$. It was also observed there was only one step of thermal degradation for PGS, a probable explanation is that the random depolymerization mechanism was accompanied by the oxidation of organic groups combined with the silicon atoms. Oxygen radicals catalyzed the depolymerization of PGS to volatile cyclic oligomers, competing with oxidative crosslinking that stabilizes the material. ${ }^{\mathbf{1 1}}$ In the case of PPGS, the resulting polyphosphoric acid from the oxidation of $\mathrm{P}$ could promote the formation of the charring char layer on the surface to prevent further thermal-oxidation degradation of inner matrix. On this occasion, oxidative crosslinking to form Si-O-Si network structure was dominant relative to degradation. Additionally, the small peak in DTG curve of PPGS at $484^{\circ} \mathrm{C}$ was probably belong to the graphitization of the benzene ring in phosphaphenanthrene structure. ${ }^{12}$ The difference in degradation course between PGS and PPGS also resulted in different charring amount. The residual char ratio at $700{ }^{\circ} \mathrm{C}$ was $36.83 \%$ for PGS but $43.57 \%$ for PPGS.

The following analysis focused on the structure and composition of the produced chars in the condensed phase. Fig. 7 showed the appearance of PGS and PPGS before and after carbonization as well as the micro-morphologies of their fracture section of the produced chars. It could be seen that the chars from PGS was broken into pieces, but the formed chars from PGGS could keep an integral shape. In addition, micromorphology of the latter also showed better continuousness and compactness than that of the former. It is obvious that the char layer of PGGS possessed higher quality.

FT-IR was firstly used to analyze the structure of the above char layers as shown in Fig. 8. The FT-IR spectra of the char of PGS and PPGS had many peaks in common, included the stretching vibration of $\mathrm{C}=\mathrm{O}$ around $1630 \mathrm{~cm}^{-1}$, the stretching vibration of $\mathrm{Si}-\mathrm{C}$ around $830 \mathrm{~cm}^{-1}$, the deviational vibration of $\mathrm{Si}-\mathrm{C}$ around $1280 \mathrm{~cm}^{-1}$, the stretching vibration absorption of Si-O-C around $800 \mathrm{~cm}^{-1}$ and stretching vibration absorption of $\mathrm{Si}-\mathrm{O}-\mathrm{Si}$ around $450 \mathrm{~cm}^{-1}$. Moreover, it could be observed that the double stretching vibration of the $\mathrm{Si}-\mathrm{O}-\mathrm{Si}$ structure around 1100 and $1040 \mathrm{~cm}^{-1}$ of PGS and PPGS before carbonization was
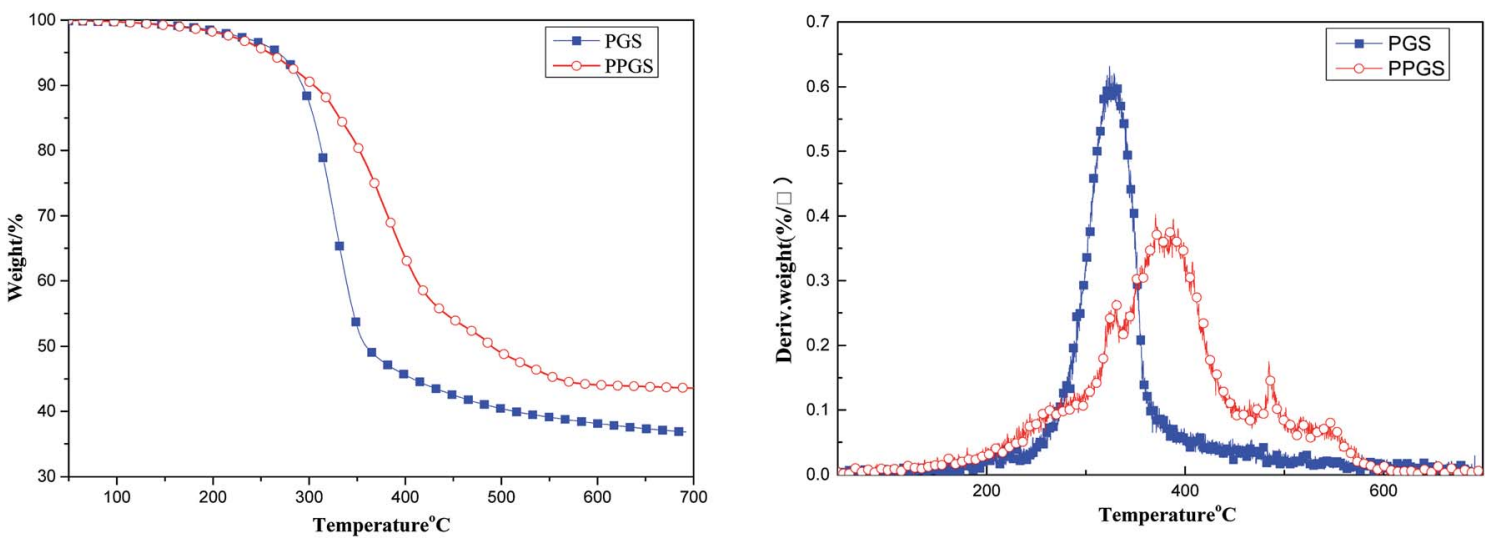

Fig. 6 TG and DTG curves of PGS and PPGS in air atmosphere. 


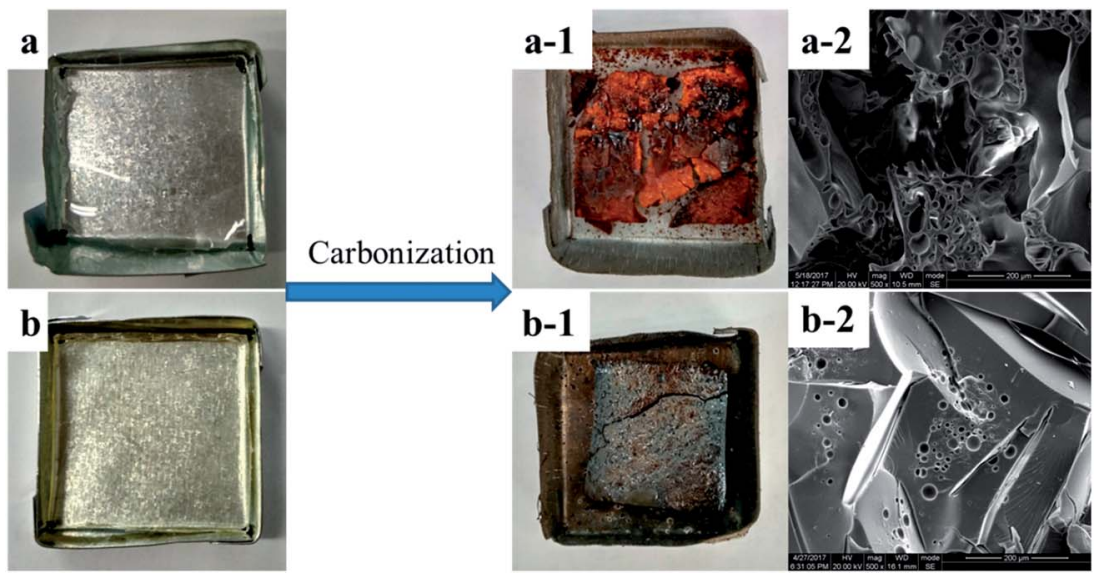

Fig. 7 The appearance and micro-morphology of (a) PGS and (b) PPGS before and after carbonization.

transformed into a single absorbance peak around $1059 \mathrm{~cm}^{-1}$ after carbonization, meanwhile this peak also became wider, it proved that most of the $\mathrm{Si}-\mathrm{O}-\mathrm{Si}$ of polysiloxane convert to the $\mathrm{Si}-\mathrm{O}-\mathrm{Si}$ of $\mathrm{SiO}_{2}$. On the other hand, there were many new peaks in the spectrum of PPGS chars relative to PGS chars. The absorption peaks at 1478, 756, 717, 700 and $669 \mathrm{~cm}^{-1}$ were respectively ascribed to stretching vibration of $\mathrm{C}=\mathrm{C}$ and deformation vibration of $\mathrm{C}-\mathrm{H}$ from the various substitution types of the benzene ring, which reflected the presence of polyaromatic structure in PPGS chars. Additionally, the absorption peaks at 602,617 and $1383 \mathrm{~cm}^{-1}$ were attributed to $\mathrm{PO}_{4}{ }^{3-}, 1450 \mathrm{~cm}^{-1}$ to the stretching vibration of $\mathrm{P}-\mathrm{Ph}$, and $1434 \mathrm{~cm}^{-1}$ to the stretching vibration of Si-Ph. The formation of $\mathrm{Si}-\mathrm{O}-\mathrm{P}(=\mathrm{O})-\mathrm{O}^{13}$ in PPGS chars probably resulted in these peaks of $\mathrm{Si}-\mathrm{O}-\mathrm{Si}$ shifted to higher wave numbers, corresponding to these peaks at 1056 and $448 \mathrm{~cm}^{-1}$ (in PGS chars) shifted to 1059 and $451 \mathrm{~cm}^{-1}$ (in PPGS chars).
To further investigate the charring process, the surface elements of the carbonized sample were analyzed by XPS in Fig. 9 and Table 2. C element is the main fuel supporting the flame (its complete combustion products: $\mathrm{CO}$ and $\mathrm{CO}_{2}$ ), its real consuming amount reflects the flame degree of materials. As Si element is non-volatile during heated, the decrease degree of $\mathrm{C}$ content relative to $\mathrm{Si}$ can evaluate the combustion degree. Compared with $\mathrm{C} / \mathrm{Si}$ ratio of PGS and PPGS before carbonization, the $\mathrm{C} / \mathrm{Si}$ ratios of theirs carbonized samples were decreased by $70.5 \%$ and $40.3 \%$ respectively. It demonstrated that the latter remained more fuel element in the condensed phase to construct the chars rather than entrance into gaseous phase for flame. In Si $2 \mathrm{p}$ spectra of both the carbonized samples, the peak at $103.8 \mathrm{eV}$ was attributed to $\mathrm{Si}-\mathrm{O}-\mathrm{Si}$, and $102.8 \mathrm{eV}$ to Si-O-C. However, a new peak at $101.9 \mathrm{eV}$ ascribed to Si-O-P could be observed for PPGS chars, which means the chemical interaction between phosphaphenanthrene structure

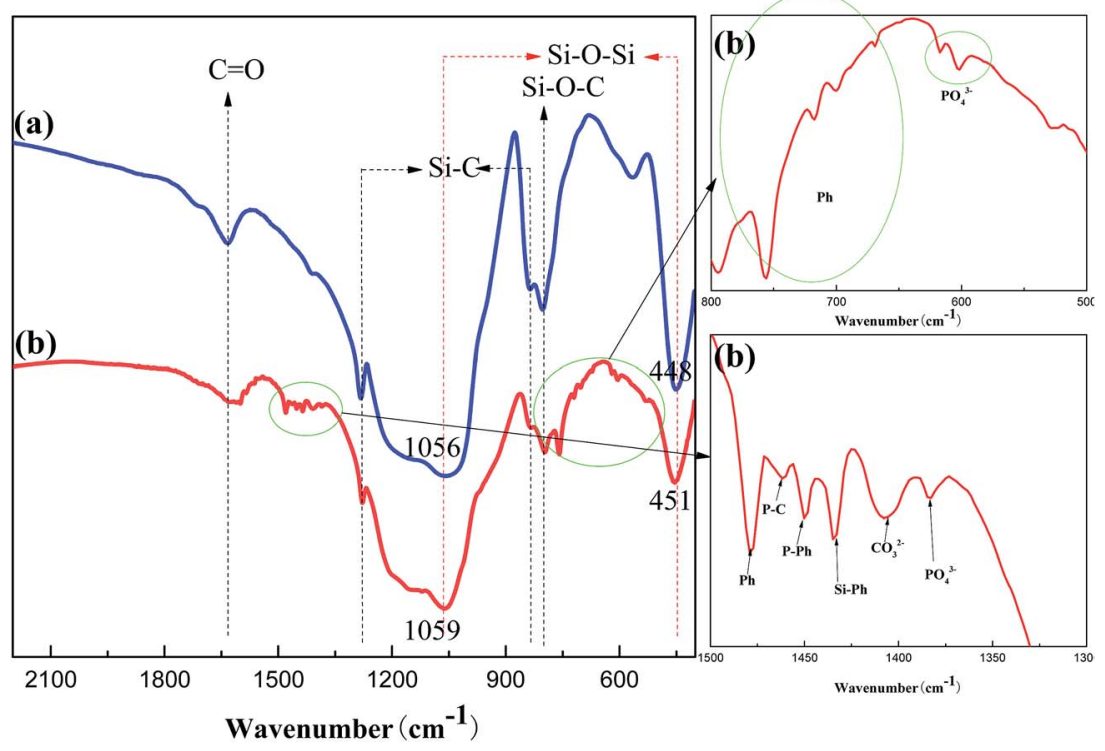

Fig. 8 FT-IR spectra of the char of (a) PGS and (b) PPGS. 

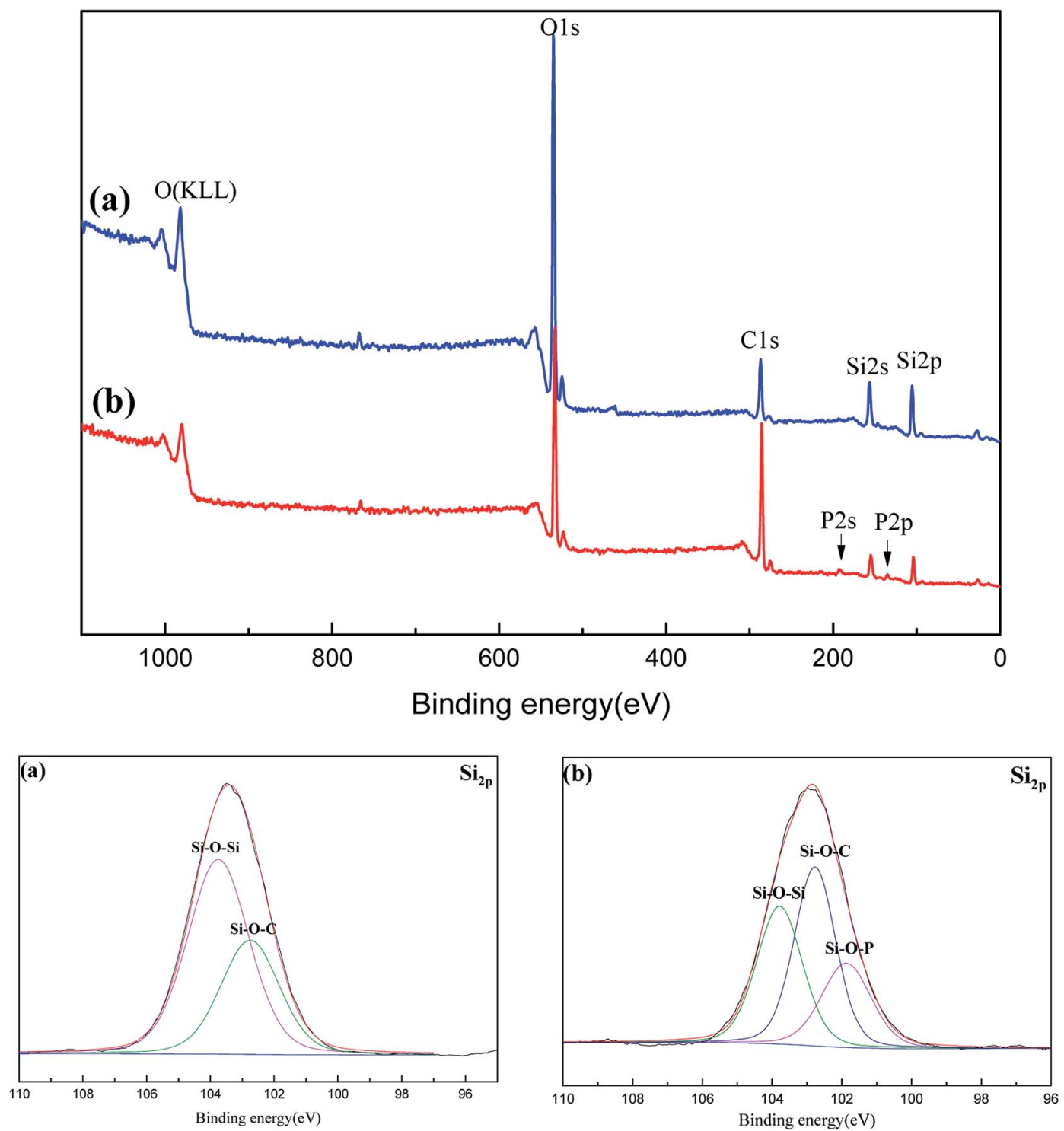

Fig. 9 XPS spectra of the carbonized (a) PGS and (b) PPGS.

Table 2 The element content of PGS and PPGS before and after carbonization

\begin{tabular}{llrllr}
\hline Element/at\% & C & \multicolumn{1}{c}{$\mathrm{Si}$} & $\mathrm{O}$ & $\mathrm{P}$ & $\mathrm{C} / \mathrm{Si}$ \\
\hline PGS (calculation value) & 54.55 & 9.09 & 36.36 & - & 6.00 \\
PPGS (calculation value) & 64.86 & 5.41 & 27.03 & 2.70 & 12.00 \\
Carbonized PGS & 27.07 & 15.27 & 57.66 & - & 1.77 \\
Carbonized PPGS & 55.90 & 7.81 & 34.94 & 1.35 & 7.16
\end{tabular}

and polysiloxane. Furthermore, higher peak of Si-O-C for PPGS chars also implied that more $-\mathrm{Si}-\mathrm{O}-\mathrm{C}(=\mathrm{O})$ - linkages generated.

Summarizing the FT-IR and XPS analysis, the charring mechanism of PPGS could be described in terms of the formation of $-\mathrm{P}(=\mathrm{O})-\mathrm{O}-\mathrm{Si}-$ and more $-\mathrm{Si}-\mathrm{O}-\mathrm{C}(=\mathrm{O})$ - linkages. These linkages connected the three dimensional net of $\mathrm{Si}(-\mathrm{O})_{4}$ and polyaromatic structure like bridges as shown in Scheme 2, thus effectively increasing both the amount and the thermal stability of the chars.

\subsection{Physical properties}

To further research the effect of the large and rigid side group on SR's mechanical properties, the dynamic mechanical behaviors of PGS and PPGS were measured. The curves of the storage modulus $\left(E^{\prime}\right)$, loss modulus $\left(E^{\prime \prime}\right)$, and $\tan \delta$ versus temperature were given respectively in Fig. 10. Compared with PGS, PPGS showed obvious improvement of $E^{\prime}$ in the glassy region due to the segmental confinement caused by large rigid phosphaphenanthrene side groups. The crosslink density of the cured product could be estimated from the plateau of the storage modulus in the rubbery state. According to the theory of rubber elasticity, the cross-linking density can be calculated using the equation $\rho=\frac{E^{\prime}}{3 R T},{ }^{\mathbf{1 4}}$ where $E^{\prime}$ is the storage modulus 


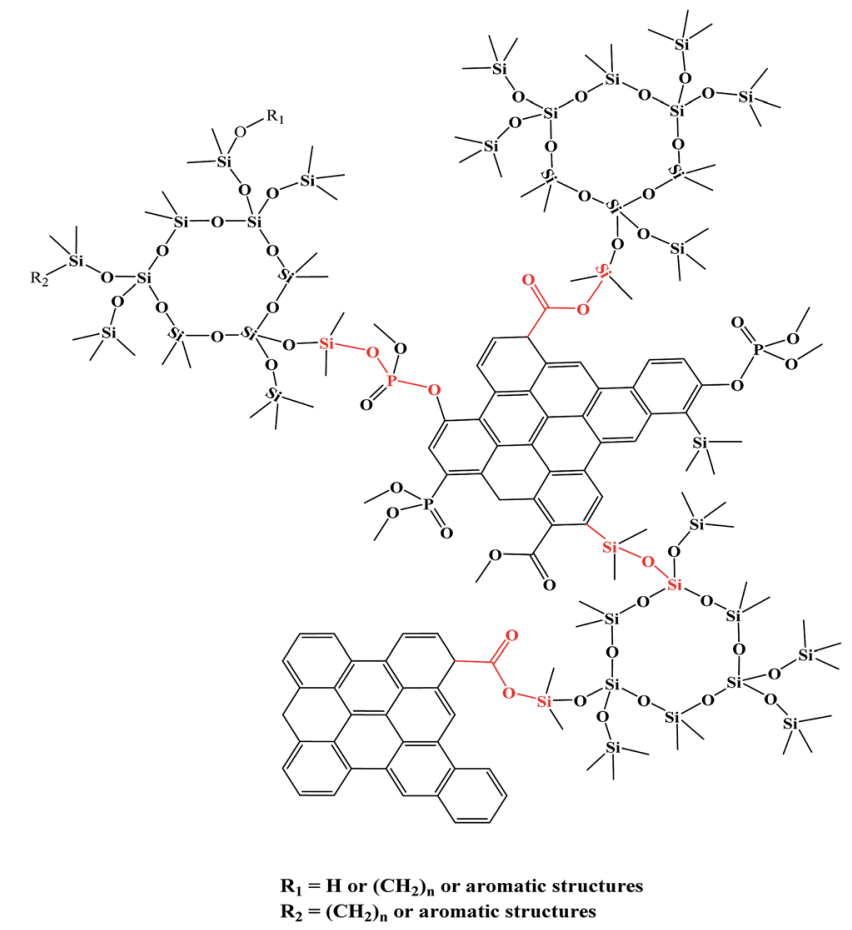

Scheme 2 Possible chemical structure of the PPGS chars.

at $T_{\mathrm{g}}+30{ }^{\circ} \mathrm{C}, R$ is the gas constant, and $T$ is the absolute temperature at $T_{\mathrm{g}}+30{ }^{\circ} \mathrm{C}$. The calculated cross-linking density of PGS was $8527 \mathrm{~mol} \mathrm{~m}^{-3}$, but PPGS was only $264 \mathrm{~mol} \mathrm{~m}^{-3}$.
Obviously, the steric hindrance of phosphaphenanthrene structure could greatly reduce the cross-linking degree. Loss modulus represents the energy dissipation because of the internal friction from the relative motion of polymer chains. PGS possessed higher cross-linking density but softer side groups, so the lower loss modulus compared to PPGS (corresponding to better viscoelasticity) showed side group had greater influence on the loss modulus than crosslinking degree. The temperature corresponding to maximum tan delta is generally regarded as $T_{\mathrm{g}}$ of a polymer. Clearly, introducing the phosphaphenanthrene structure in the SR resulted in substantial increase of $T_{\mathrm{g}}$.

Besides, the static mechanical properties of the above SR materials were also exhibited in Table 3. PPGS had higher tensile strength, elastic modulus, elongation at break than PGS. A possible reason is too high crosslinking degree of the latter increase the brittleness, but the steric hindrance of phosphaphenanthrene structure could avoid excessive crosslinking of SR, hence kept better toughness and strength.

Transparence is an important advantage for SR materials. However, adding flame retardants in SR matrix generally seriously deteriorate the transparence. By contrast, intrinsic flame retardant SR could well overcome the problem. Fig. 11 showed the light transmission ratio (LTR) of PGS, PPGS and DOPO/PGS mixture (physical addition). The flame retardant mixture system was completely opaque. Compared with PGS, PPGS displayed somewhat decrease in transmission ratio, but still maintained as high as $88.2 \%$ of LTR.
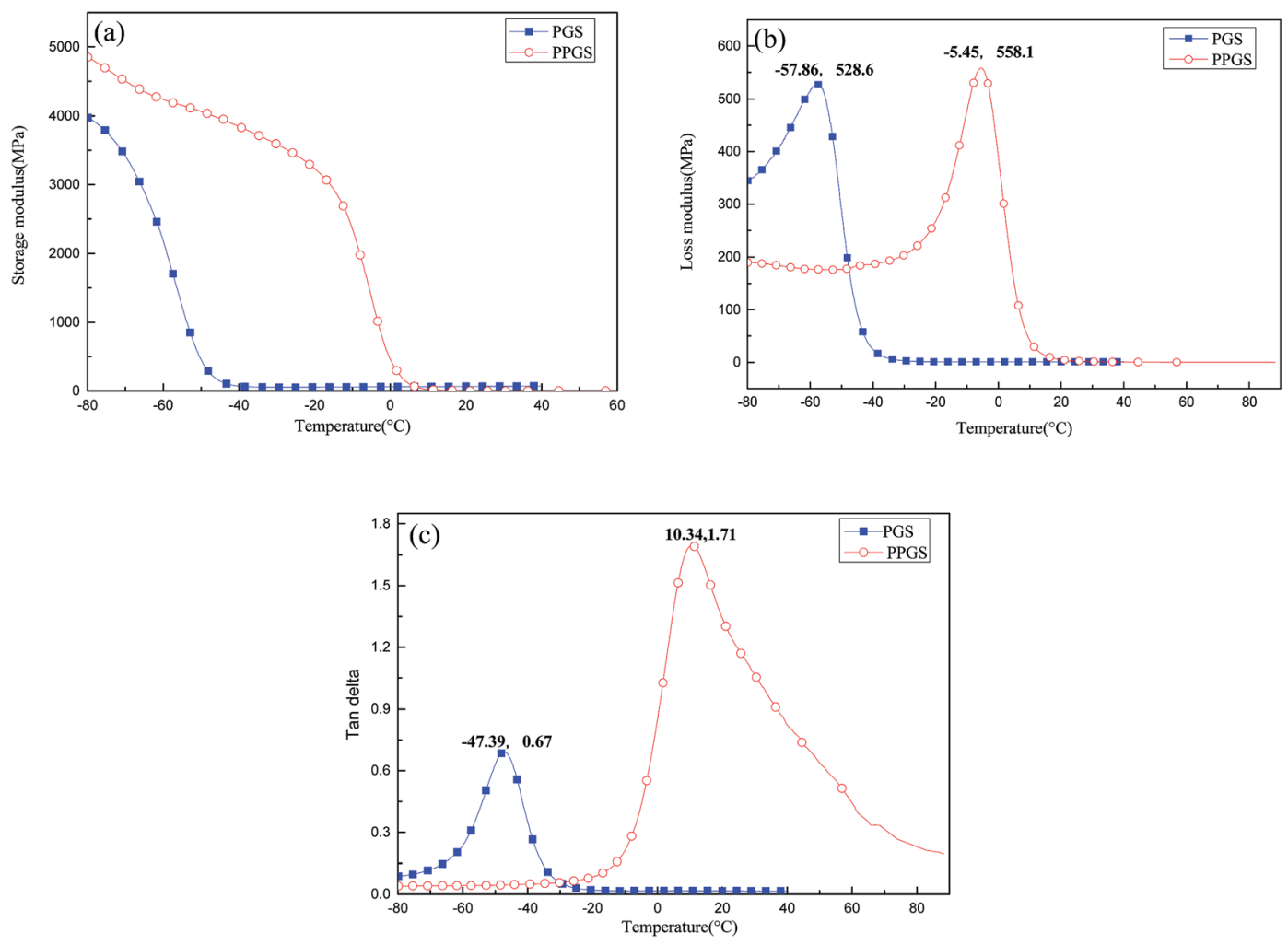

Fig. 10 DMA results of PGS and PPGS. 
Table 3 The mechanical properties of PGS and PPGS

\begin{tabular}{|c|c|c|c|}
\hline Samples & Tensile strength (MPa) & Elastic modulus (MPa) & Elongation at break (\%) \\
\hline PGS & $4.03 \pm 0.88$ & $20.66 \pm 4.80$ & $16.96 \pm 0.96$ \\
\hline PPGS & $5.27 \pm 0.27$ & $27.02 \pm 1.02$ & $29.00 \pm 1.50$ \\
\hline
\end{tabular}
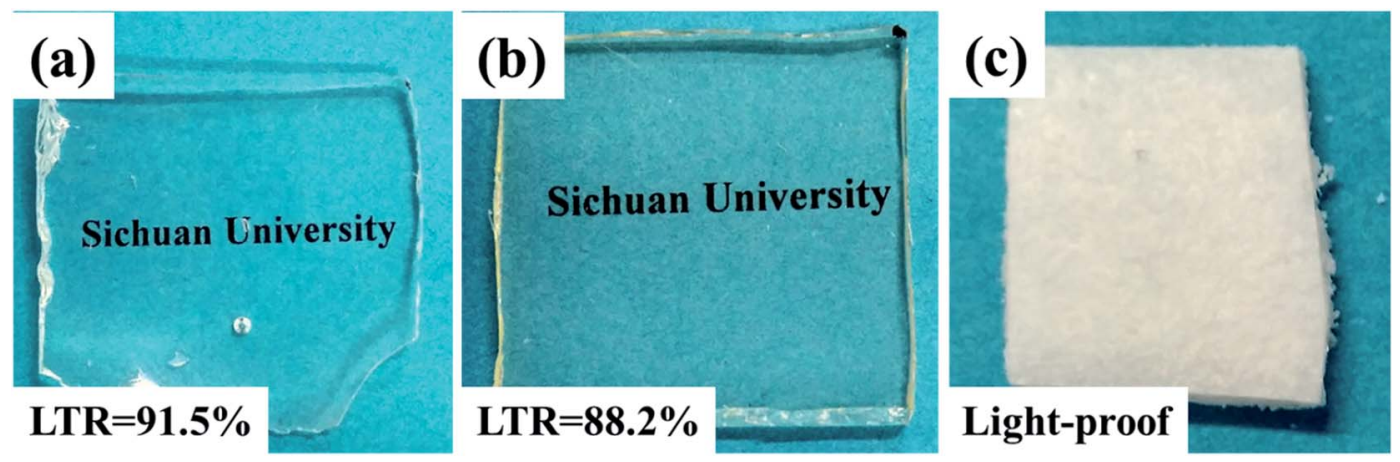

Fig. 11 Comparison of the transparency of (a) PGS, (b) PPGS and (c) DOPO/PGS mixture.

\section{Conclusions}

PPGS with intrinsic flame retardance was successfully synthesized and confirmed. Due to the introduction of phosphaphenanthrene structure, this SR could achieve UL94-V0 rating and as high as $42.3 \%$ of LOI, as well as greatly decreased HRR and THR, showing much better flame retardancy in comparison to PGS. The composition and bond forms revealed the interaction between phosphaphenanthrene structure and the silsesquioxanes in the condensed phase, which can be described in terms of the resulting $-\mathrm{P}(=\mathrm{O})-\mathrm{O}-\mathrm{Si}-$ and more $-\mathrm{Si}-\mathrm{O}-\mathrm{C}(=\mathrm{O})-$ linkages connecting the three dimensional net of $\mathrm{Si}(-\mathrm{O})_{4}$ and polyaromatic carbon structures like bridges, thus further increasing both the amount and the thermal stability of the char yield. On the other hand, PPGS also displayed excellent comprehensive performance including high transparency with a light transmission ratio of $88.2 \%$, as well as better mechanical properties due to appropriate cross-linking degree. Based on the excellent performance above, it is believable that such an intrinsic flame retardant SR shows a promise in future commercialization.

\section{Conflicts of interest}

There are no conflicts of interest to declare.

\section{Acknowledgements}

Wei Chen and Yuansen Liu contributed equally to this work. The authors acknowledge financial support from the National Natural Science Foundation of China (No. 51473095), the Program of Innovative Research Team for Young Scientists of Sichuan Province (2016TD0010), Xiamen Southern Oceanographic Center (14GQT61HJ31, 15GZP023NF01), Scientific and
Technological Projects of Xiamen City (3502Z20172010) and Science and Technology Planning Project of Fujian Province, China (2015Y0034).

\section{References}

1 S. Gunasekaran, R. K. Natarajan, A. Kala and R. Jagannathan, Indian J. Pure Appl. Phys., 2008, 46, 733-737.

2 J. Wen, Y. Li, Y. Zuo, G. Zhou, J. Li, L. Jiang and W. Xu, Mater. Lett., 2008, 62, 3307-3309.

3 S. Hamdani, C. Longuet, D. Perrin, J.-M. Lopez-cuesta and F. Ganachaud, Polym. Degrad. Stab., 2009, 94, 465-495.

4 J. L. Zhuo, J. Dong, C. M. Jiao and X. L. Chen, Plast., Rubber Compos., 2013, 42, 239-243.

5 A. Genovese and R. A. Shanks, Composites, Part A, 2008, 39, 398-405.

6 M. M. Demir, Y. Z. Menceloglu and B. Erman, Polymer, 2005, 46, 4127-4134.

7 E.-S. Park, J. Appl. Polym. Sci., 2007, 105, 460-468.

8 L. Yang, Y. Hu, H. D. Lu and L. Song, J. Appl. Polym. Sci., 2006, 99, 3275-3280.

9 X. Chen, J. Zhuo, W. Song, C. Jiao, Y. Qian and S. Li, Polym. Adv. Technol., 2014, 25, 1530-1537.

10 L. Hong and X. Hu, J. Macromol. Sci., Part B: Phys., 2016, 55, 175-187.

11 G. Camino, S. M. Lomakin and M. Lazzari, Polymer, 2001, 42, 2395-2402.

12 S. Yang, J. Wang, S. Huo, M. Wang and L. Cheng, Ind. Eng. Chem. Res., 2015, 54, 7777-7786.

13 W. Zhang, X. Li, H. Fan and R. Yang, Polym. Degrad. Stab., 2012, 97, 2241-2248.

14 W. Liu, R. Zhou, H. L. S. Goh, S. Huang and X. Lu, ACS Appl. Mater. Interfaces, 2014, 6, 5810-5817. 